\title{
On Niall Ferguson's “Complexity and Collapse”
}

Theodore Modis*

\section{A special lens}

Ferguson presents a refreshing new look through which empires can be seen ending discontinuously and abruptly rather than slowly and smoothly as they came into existence. But he has a particular way of looking at things and perception, as he correctly points out, plays a crucial role. For example, the declines of the Roman Empire and the USSR can be equally well-if not better-seen through an opposite lens.

"Through this lens," Ferguson argues, "Rome's fall was sudden and dramatic". But Rome fell in 476 whereas civil war had become a recurring problem there already in 180 and barbarian invasions or migrations had become endemic in the 3rd and 4th centuries. He similarly sees USSR's dismantling as abrupt via his lens. But USSR's end can appear smooth and predictable via an ordinary natural-growth approach as follows.

The perception of a state's well being is not necessarily best reflected on the size of its economy. USSR's enormous nuclear arsenal was considered a handicap by most people in 1985. The zenith of the USSR-by popular perception-had been reached much earlier in 1957 when the first satellite ever, SPUTNIK, circled the earth putting to shame the US, the world's most affluent and technologically advanced country. But from then onward, the USSR began losing ground indisputably, first with the Cuba crisis

*E-mail address: tmodis@yahoo.com

URL: http://www.growth-dynamics.com. 
(1962) and then with the moon race (1969) that was doomed for lack of funds. The Soviets could not afford adequate testing of their superior rocket, and it exploded during the critical launch.

An astute observer in 1969 could have noticed that with a beginning in 1917 and an apogee in 1957, a life cycle being symmetric to a first approximation could herald a death for USSR by 1997. A more sophisticated observer could have incorporated the large chaotic fluctuations that generally appear during the early and late stages of any natural-growth process and thus expect large abrupt changes in the USSR during the several years preceding 1997. In this light USSR's withdrawal from Afghanistan and the fall of the Berlin Wall hardly deserve characterizations as "mirabilis".

\section{Fashionable science}

Chaos, complexity, and adaptive systems became fashionable in the late 20th century but they do not necessarily fit all situations. Ferguson is ready to throw all previous approaches in the dustbin (some of which were classics like Keynes, Darwin, and Adam Smith) in favor of the new doctrine. But as the advent of quantum mechanics did not diminish in any way the usefulness and effectiveness of classical physics so do logistic growth and the more general Volterra-Lotka equations continue proving effective in modeling markets, products, and the dynamics of "species" growing in competition.

The generalized Volterra-Lotka formulation can account for all types of interference between competing species. One might justifiably expect that in its full generality, the formulation in a discrete form, with cross terms to account for all interrelations between competing species, would give a complete picture, in which growth, chaos, self-organization, complex adaptive systems, and many other trendy academic pastimes ensue as special cases.

The Mayans did not have to end up in a catastrophic collapse, which is only one of the possible solutions of the Volterra-Lotka system of equations. Other solutions include symbiotic and predator-prey relationships both of which yield stable, if cyclical survival. Just as a rabbit population stabilizes around the maximum number of individuals its eco-niche can accommodate, so the Mayans could have ended up with a different less catastrophic fate. They may have been unlucky or they may have not successfully put to work the "adaptive" aspect of their complex adaptive system.

Ferguson makes the statement "neither interest rates at zero nor fiscal stimulus can achieve a sustainable recovery if people in the United States and abroad collectively decide, overnight, that such measures will lead to much higher inflation rates or outright default." This may be true but one may be tempted to replace "collectively decide, overnight" with collectively adapt, progressively" and end up with no catastrophe, because both alternatives are solutions of the Volterra-Lotka system of equations.

\section{Chaos and order}

A state of chaos is not a permanent condition. Chaotic fluctuations appear in the beginning and at the end of a natural-growth process. The middle rapid-growth phase is rather orderly. It has been demonstrated both with theory and case studies that successive growth steps-typical of sustained growth-are characterized by an alternation between chaos and order [1-4]. One example of such alternation between chaos and order is shown in the figure below (Fig. 1).

It can be seen that singular events such as the economic collapse triggered by the stock-market crash of 1929 and WWII correlate to larger fluctuations in the figure. More interestingly, the stagnating periods 1920-1940 and 1980-2000 characterized by chaotic fluctuations coincide with the saturation of many large industrialization growth processes. Combining data from works by C. Marchetti, N. Nakicenovic, A. Grubler, and myself I was able to document 44 industrialization processes worldwide-mostly concerning the construction of infrastructures and the substitution and diffusion of technologies-all of which reached their ceiling in one of these two chaotic periods [5-7].

It makes sense that the origins of recent outbursts in complexity and chaos in western economies that Ferguson is concerned about are linked to natural-growth processes reaching their ceilings.

\section{The Greek crisis}

The Greek fiscal crisis cannot be blamed on investors' speculative tactics. Yes, markets and governments constitute a feedback loop whereby crises make investors demand higher interest rates that exacerbate the crises, but the Greek crisis has cultural roots and originated well before investors came into the picture. And assuming collapse will eventually be avoided, the ensued political crisis may constitute Greece's only chance for escaping from an eternal developing-country status. No smooth alternative existed for Greeks to "shape up". An ancient Greek proverb says there is no bad without some good in it. This crisis could be a blessing in disguise for Greeks.

\section{In conclusion}

As much as Ferguson's lens may throw new light in our understanding of complex political and economic structures, classifying a system as wholly nondeterministic is of little use to us as a guide on how to act. Moreover, it represents only one of the many possible solutions of the system as described by the Volterra-Lotka equations. Other solutions predict smoother evolutions for which the future can be anticipated, appropriate strategies can be set, and actions can be taken. Dinosaurs lived "on the edge of chaos" for quite some time (had grown too big for their own good, partook in an "imperial overstretch" and a final collapse due to a 


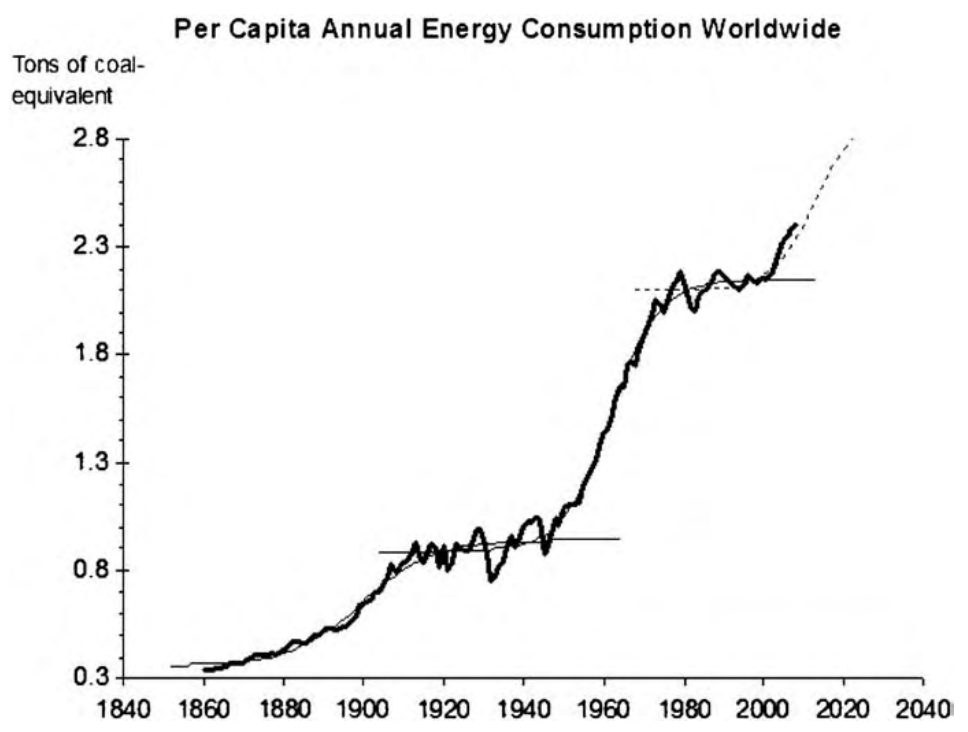

Fig. 1. Raw data (thick black line) and two logistic fits (thin lines). The intermittent line is a suggestion for a future scenario. The yearly data points cover up to the beginning of 2009. Data source: Statistical Abstract of the United States, U.S. Department of Commerce, Bureau of the Census.

meteorite collision or otherwise). In any case it is questionable how much could have been done to avert a fate of extinction by any intelligent agent at the time. It remains that dinosaurs achieved an enviable life span.

\section{References}

[1] J. Ausubel, A. Grubler, N. Nakicenovic, Carbon dioxide emissions in methane economy, Clim. Change 12 (1988) 245-263.

[2] T. Modis, A. Debecker, Chaoslike states can be expected before and after logistic growth, Technol. Forecasting Soc. Change 41 (1992) 111-120.

[3] T. Modis, Fractal aspects of natural growth, Technol. Forecasting Soc. Change 47 (1994) 63-73.

[4] H. Montrey, J. Utterback, Current status and future of structural panels in wood products industry, Technol. Forecasting Soc. Change 38 (1990) 15-35.

[5] A. Grubler, The Rise and Fall of Infrastructures, Physica-Verlag, Heidelberg, 1989.

[6] C. Marchetti, Recession 1983: ten more years to go? Technol. Forecasting Soc. Change 24 (1983) 331-342.

[7] T. Modis, Predictions, Simon \& Schuster, New York, 1992.

Tessaleno Devezas is a physicist and systems theorist, Associate Professor with Habilitation at the Department of Electromechanical Engineering, Universidade da Beira Interior (UBI), P-6200-001 Covilhã, Portugal, lecturing Materials Science and Engineering, New Materials, Technological Forecasting, and Innovation and Technology Management for undergraduate and graduate engineering students since July 1, 1992. His main research interests: Technological Forecasting, Futures Studies, Socioeconomic Long Waves, Evolutionary Economics, Technological Evolution, Innovation Dynamics and New Materials.

Harold A. Linstone is University Professor Emeritus at Portland State University and editor-in-chief of this Journal. His most recent book is Decision Making for Technology Executives: Using Multiple Perspectives to Improve Performance (Artech House, 1999). Prior to his academic position he was Associate Director of Corporate Planning-Systems Analysis at the Lockheed Corporation. His M.A. and Ph.D. degrees are in Mathematics.

George Modelski is Professor Emeritus in the University of Washington, Seattle. His most recent books include Globalization as Evolutionary Process (co-editor, 2008), and World Cities: -3000 to 2000 (2003). His Evolutionary World Politics website may be accessed on http://www.faculty.washington.edu/modelski. His postal address is 2510 Virginia Avenue NW, Washington DC 20037, US0041.

Theodore Modis holds a Masters in Electrical Engineering and a PhD in Physics, both from Columbia University, New York. Before founding Growth Dynamics in 1994, he worked at Digital Equipment Corporation as the head of a management science consultants group for over ten years. Previously, he carried out research in particle-physics experiments at Brookhaven National Laboratory and Europe's CERN. He has taught at Columbia University, the University of Geneva, the European business schools INSEAD and IMD, and the leadership school DUXX, in Monterrey, Mexico. He is the author-coauthor to about 100 articles in scientific, business, and other journals, and six books. 